\title{
Factors affecting Baker cyst volume, with emphasis on cartilage lesion degree and effusion in the young and middle-aged population
}

\author{
Murat Saylik', Kemal Gokkus ${ }^{2^{*}}$ (1) and M. S. Sahin ${ }^{2}$
}

\begin{abstract}
Background: The principal aim of this study was to investigate the presence of factors affecting Baker's cyst volume in young and middle-aged populations.

Methods: Open cyst excision with valve and capsule repair, as well as knee arthroscopy, were used to treat eightyfive patients. The cases were categorized in terms of age, effusion, chondral lesion degree, meniscal tear degree, and Lindgren scores. An ultrasonography (USG) device was used to calculate the cyst volume. The IBM-SPSS 22 program was used for statistical analysis and to assess the relationships between variables using Spearman's correlation tests.

Results: The degree of chondral lesion was moderately and positively correlated with cyst volume in the total population (correlation coefficient: 0.469; $\mathrm{p}<0.05$ ).

The degree of the chondral lesion was moderately and positively correlated with the degree of effusion (correlation coefficient: $0.492 ; p<0.005$ ). The cyst volume was weakly and positively correlated with the degree of effusion (correlation coefficient: 0.20 ; the correlation was at the limits of statistical significance $p=0.07<0.08$ ).
\end{abstract}

Conclusions: This study revealed that an increase in chondral lesion severity increases the amount of effusion and cyst volume.

Keywords: Cartilage, Baker's cyst volume, Knee arthroscopy, Chondral lesion, Popliteal cyst

\section{Introduction}

Generally, joint pathologies, such as chondral lesions and meniscal tears, cause effusion, which leads to an increase in the cyst (Baker) volume [1]. A cystic mass with a large effusion within the popliteal region of the knee was first reported by Guillaume Dupuytren in 1829 [2]. In 1840, Robert Adams explained the correlation between rheumatoid arthritis and swelling of the cystic mass [3].

\footnotetext{
${ }^{*}$ Correspondence: kemalg@baskent.edu.tr

${ }^{2}$ Department of Orthopaedics and Traumatology, Baskent University Alanya Research and Practice Center, Saray Mahallesi Yunus Emre Caddesi No:1 07400, Alanya, Antalya, Turkey

Full list of author information is available at the end of the article
}

Anatomical dissection studies determined the mass as the distension of the bursa located between the semimembranous tendon and the medial head of the gastrocnemius muscle [4-6]. In 1856, Foucher also reported the case of a recurrent cyst that became firm with full knee extension and softer with flexion, which led to the conditions being subsequently coined "Foucher's Sign" [7].

In 1877, Baker confirmed the entity as a "bursal distention" caused by the trapping of fluid in a bursa with a direct relation to the semi-membranous tendon. Moreover, he explained that the communication between the cyst and the joint synovium behaves as a one-way valve, with fluid leaking into the bursa and no possible flow in original author(s) and the source, provide a link to the Creative Commons licence, and indicate if changes were made. The images or other third party material in this article are included in the article's Creative Commons licence, unless indicated otherwise in a credit line to the material. If material is not included in the article's Creative Commons licence and your intended use is not permitted by statutory regulation or exceeds the permitted use, you will need to obtain permission directly from the copyright holder. To view a copy of this licence, visit http://creativecommons.org/licenses/by/4.0/. The Creative Commons Public Domain Dedication waiver (http://creativeco mmons.org/publicdomain/zero/1.0/) applies to the data made available in this article, unless otherwise stated in a credit line to the data. 
the reverse direction. Baker defined the possibility of a ruptured bursa resembling venous thrombosis. For that purpose, Baker's name was incorporated with the clinical entity of a popliteal cyst, that is, "Baker's cyst" $[8,9]$.

Baker's cyst is strongly associated with the existence of intra-articular pathologies, such as chondral lesions and meniscal tears, with a reported incidence of approximately $94 \%$ in some series [10]. Any pathology that causes significant and persistent joint effusion can lead to Baker's cyst [11]; however, this will depend not only on the presence of the pathology, but also on its extent and severity. The literature can be divided into two groups based on this: the first group of studies correlates the extent of pathologies with Baker's cyst [12-14], while the other group correlates only with the presence and absence of pathologies [15-22].

However, the quantification of cyst size (calculating the approximate volume) and a probable relationship between cartilage lesion degree, effusion degree, and cyst volume were only reported in one study by Balik et al. [13]. In their study, Rupp et al. [21] reported that articular cartilage lesions were most often associated with a popliteal cyst, whereas Cao et al. [20] found that popliteal cyst or sub-gastrocnemius bursitis were significantly and positively associated with knee cartilage defects at the medial and lateral tibiofemoral sites, before and after adjustment for age, sex, BMI, disease status, and knee radiographic features.

The main objective of this study was to assess the factors affecting Baker's cyst volume, its importance on effusion, and the degree of cartilage damage in the young and middle-aged population.

\section{Material and method}

This retrospective study was approved by the ethics committee of our institution and was registered under the protocol.

The present study was conducted in accordance with a recognized international standard, including the principles of the Declaration of Helsinki.

Data from 164 patients with Baker's cysts $\geq 3 \mathrm{~cm}$ in diameter were collected between January 2009 and December 2017. In the current study, cysts with a diameter of $\geq 3 \mathrm{~cm}$ were included, because we assumed that $3 \mathrm{~cm}$ was the asymptomatic limit, referring to the study by Tschirch et al. [23]. Screening included all patients with a popliteal mass or mass-like symptoms, including pain in the popliteal fossa or various degrees of joint limitation, consistent with the physical findings of a probable Baker's cyst. All information was obtained using ultrasound (USG) and magnetic resonance imaging (MRI). Eighteen patients with seronegative and seropositive arthritis were excluded from this study. All remaining 146 patients received conservative treatment for approximately six months before the decision to proceed with surgical treatment was made. Conservative treatment included the application of ice, rest, and the use of non-steroidal anti-inflammatory drugs. In our study group, improvement in symptomology was achieved with conservative treatment in 17 patients, and another 17 patients improved with the use of intracystic injections. Five patients were lost during followup, with the remaining 112 patients (equating to a total of 114 knees) resisting conservative treatment. Patients with osteophytes and advanced joint narrowing indicative of mild to severe osteoarthritis identified by direct radiography and classified according to the KellgrenLawrence scale, as well as those with Kellgren-Lawrence grade 3-4 osteoarthritis, were excluded from the study to avoid bias resulting from likely age-related osteoarthritis. (27 patients, 29 knees). In addition, the patients (young and middle-aged) who had chondral lesions resulting from a sprain or any other trauma to the knee were also included in the current study.

Finally, 85 patients (53 women and 32 men) who were treated with posterior open cystectomy with valve and repair of the posterior capsule, in addition to arthroscopic treatment of intra-articular lesions, were included in the study.

The patients were categorized according to age, sex, effusion level, chondral lesion degree, meniscal tear degree, and Rauschning-Lindgren scores (Table 1). The Rauschning-Lindgren functional score is shown in Table 2. The mean age of the total population was determined to be $46.9 \pm 9.2$, from a range of 22 to 59 (See Table 3), the chondral lesion degree was graded by applying the modified Outerbridge [24] classification (See Figs. 1 and 2 and Table 4), and the graded results were confirmed with arthroscopy (See Fig. 1).

Using MR images, the meniscal tears were classified as normal meniscus, Grade 0, with Grades I and II having an intra-meniscal signal that did not extend to the free edge. Grade III had a signal shift that abutted the meniscal free border, suggesting a meniscal tear [25]. The Lindgren score change and distribution of the patients regarding age, chondral lesion, effusion, and degree of meniscal injury were recorded (See Table 1).

For a linear statistical evaluation, cases with two or more separate chondral lesions, such as combined patellofemoral and femoral medial condyle lesions, were assessed. In other words, a case with a medial femoral condyle Grade 3 lesion and an additional patellar cartilage Grade 2 lesion was recorded as Grade 5, suggesting that each chondral lesion had the potential to generate effusion of its own. 
Table 1 For analysis, cases were categorized in age, sex, effusion, chondral lesion degree, meniscal tear degree, and the RauschningLindgren knee scores

\begin{tabular}{|c|c|c|c|c|c|c|c|c|c|}
\hline \multicolumn{10}{|c|}{ Lindgren score value change \&distribution of the patients regarding to age, chondral lesion, effusion and meniscal degree } \\
\hline & Age & Gender & $\begin{array}{l}\text { Meniscal tear } \\
\text { degree }\end{array}$ & $\begin{array}{l}\text { Chondral } \\
\text { lesion degree }\end{array}$ & $\begin{array}{l}\text { Effusion } \\
\text { degree }\end{array}$ & $\begin{array}{l}\text { Three } \\
\text { dimensions of } \\
\text { cyst }\end{array}$ & Cyst Volume $\left(\mathrm{cm}^{3}\right)$ & $\begin{array}{l}\text { Lindgren } \\
\text { pre op }\end{array}$ & $\begin{array}{l}\text { Lindgren } \\
\text { postop }\end{array}$ \\
\hline 1 & 49 & $\mathrm{~F}$ & 2 & 5 & moderate & $5 \times 3 \times 3$ & 23,535 & 3 & 1 \\
\hline 2 & 53 & $\mathrm{~F}$ & 2 & 1 & minimal & $4 \times 2,5 \times 1.8$ & 9.414 & 1 & 0 \\
\hline 3 & 44 & M & 0 & 4 & moderate & $6 \times 3 \times 4$ & 37.656 & 2 & 0 \\
\hline 4 & 43 & $F$ & 2 & 0 & minimal & $4 \times 2,5 \times 3$ & 15.69 & 1 & 0 \\
\hline 5 & 44 & $\mathrm{~F}$ & 3 & 5 & severe & $5,5 \times 2,5 \times 1,1$ & 7.91 & 3 & 1 \\
\hline 6 & 53 & $\mathrm{~F}$ & 2 & 0 & moderate & $5 \times 3 \times 2,5$ & 19.61 & 2 & 0 \\
\hline 7 & 53 & M & 2 & 0 & minimal & $3,5 \times 2 \times 3$ & 10.983 & 1 & 0 \\
\hline 8 & 58 & M & 3 & 2 & severe & $3 \times 2 \times 1,5$ & 4.707 & 2 & 0 \\
\hline 9 & 45 & $F$ & 2 & 2 & minimal & $4 \times 2 \times 2,5$ & 10.46 & 1 & 0 \\
\hline 10 & 54 & $\mathrm{~F}$ & 2 & 5 & severe & $7.2 \times 3,5 \times 2,5$ & 32.949 & 2 & 1 \\
\hline 11 & 34 & $\mathrm{~F}$ & 2 & 2 & minimal & $5.2 \times 2 \times 3$ & 16.317 & 1 & 0 \\
\hline 12 & 50 & $\mathrm{~F}$ & 2 & 3 & severe & $3,5 \times 1,5 \times 2$ & 5,491 & 2 & 1 \\
\hline 13 & 50 & $\mathrm{~F}$ & 2 & 2 & moderate & $4,5 \times 3 \times 2,5$ & 17.651 & 2 & 0 \\
\hline 14 & 31 & $\mathrm{~F}$ & 0 & 3 & moderate & $3,5 \times 2 \times 3$ & 10.983 & 2 & 1 \\
\hline 15 & 34 & M & 1 & 2 & moderate & $5 \times 1.7 \times 2$ & 8.891 & 2 & 0 \\
\hline 16 & 56 & M & 1 & 3 & severe & $5 \times 1.6 \times 2$ & 8,368 & 3 & 1 \\
\hline 17 & 46 & M & 1 & 2 & moderate & $3,5 \times 2 \times 1,5$ & 5.491 & 1 & 0 \\
\hline 18 & 47 & $F$ & 1 & 3 & minimal & $3 \times 2 \times 6$ & 18.828 & 2 & 0 \\
\hline 19 & 44 & $M$ & 0 & 4 & moderate & $4.2 \times 2 \times 1,5$ & 6.589 & 2 & 0 \\
\hline 20 & 31 & $\mathrm{~F}$ & 1 & 3 & minimal & $3.2 \times 2,5 \times 2$ & 8.368 & 1 & 0 \\
\hline 21 & 39 & $\mathrm{~F}$ & 0 & 3 & moderate & $5.8 \times 3.7 \times 2.3$ & 25,814 & 2 & 1 \\
\hline 22 & 54 & M & 1 & 4 & severe & $4 \times 2,5 \times \mathbf{2}, \mathbf{1}$ & 10.983 & 2 & 0 \\
\hline 23 & 33 & M & 2 & 3 & moderate & $3.8 \times 2 \times 1.8$ & 7.154 & 2 & 0 \\
\hline 24 & 50 & M & 2 & 4 & severe & $6 \times 2,5 \times 1,5$ & 11.767 & 2 & 1 \\
\hline 25 & 30 & $\mathrm{~F}$ & 2 & 1 & minimal & $4,5 \times 3 \times 1,5$ & 10.59 & 1 & 0 \\
\hline 26 & 43 & $\mathrm{~F}$ & 0 & 2 & minimal & $4,5 \times 3 \times 2$ & 14.121 & 1 & 0 \\
\hline 27 & 22 & $M$ & 2 & 0 & severe & $4 \times 3 \times 2,5$ & 15.69 & 1 & 0 \\
\hline 28 & 51 & $\mathrm{~F}$ & 2 & 4 & severe & $4 \times 2,5 \times 2$ & 10.46 & 2 & 1 \\
\hline 29 & 57 & $\mathrm{~F}$ & 2 & 4 & moderate & $6.2 \times 2,5 \times 3,5$ & 28,372 & 2 & 1 \\
\hline 30 & 44 & F & 1 & 7 & severe & $10,5 \times 2,5 \times 3$ & 41.186 & 3 & 0 \\
\hline 31 & 49 & $F$ & 1 & 2 & minimal & $3,5 \times 2,5 \times 3$ & 13.728 & 2 & 0 \\
\hline 32 & 31 & $M$ & 2 & 2 & minimal & $3,5 \times 4,5 \times 2$ & 16.474 & 1 & 0 \\
\hline 33 & 53 & $\mathrm{~F}$ & 1 & 2 & minimal & $6 \times 1,5 \times 2$ & 9.414 & 1 & 0 \\
\hline 34 & 57 & $\mathrm{~F}$ & 2 & 8 & severe & $8,5 \times 4 \times 3$ & 53.346 & 2 & 1 \\
\hline 35 & 59 & $\mathrm{~F}$ & 1 & 3 & minimal & $3,5 \times 4 \times 4,5$ & 32.949 & 1 & 0 \\
\hline 36 & 43 & M & 1 & 4 & minimal & $3,5 \times 4,5 \times 3$ & 24.711 & 2 & 1 \\
\hline 37 & 42 & $\mathrm{~F}$ & 0 & 7 & severe & $9 \times 3,5 \times 2,5$ & 41.186 & 1 & 0 \\
\hline 38 & 28 & $M$ & 2 & 2 & minimal & $3 \times 5 \times 2$ & 15.69 & 1 & 0 \\
\hline 39 & 59 & $\mathrm{~F}$ & 2 & 4 & severe & $6 \times 1,5 \times 2,5$ & 11.767 & 2 & 1 \\
\hline 40 & 56 & $\mathrm{~F}$ & 1 & 3 & moderate & $5 \times 4 \times 2,5$ & 26.15 & 2 & 1 \\
\hline 41 & 41 & M & 2 & 2 & minimal & $3,5 \times 2 \times 2,5$ & 9.152 & 2 & 0 \\
\hline 42 & 45 & $\mathrm{~F}$ & 2 & 4 & severe & $6 \times 3,5 \times 1$ & 10.983 & 2 & 1 \\
\hline 43 & 49 & M & 0 & 2 & minimal & $5 \times 3 \times 2,5$ & 19.61 & 1 & 0 \\
\hline 44 & 59 & M & 3 & 4 & minimal & $5 \times 2,48 \times \mathbf{2}, \mathbf{3}$ & 14.915 & 3 & 1 \\
\hline 45 & 58 & M & 2 & 2 & minimal & $3,5 \times 1.7 \times 1,5$ & 4.66 & 2 & 0 \\
\hline 46 & 50 & $\mathrm{~F}$ & 2 & 2 & minimal & $3,5 \times 2.8 \times 2.3$ & 11.788 & 1 & 0 \\
\hline
\end{tabular}


Table 1 (continued)

Lindgren score value change \&distribution of the patients regarding to age , chondral lesion, effusion and meniscal degree

\begin{tabular}{|c|c|c|c|c|c|c|c|c|c|}
\hline & Age & Gender & $\begin{array}{l}\text { Meniscal tear } \\
\text { degree }\end{array}$ & $\begin{array}{l}\text { Chondral } \\
\text { lesion degree }\end{array}$ & $\begin{array}{l}\text { Effusion } \\
\text { degree }\end{array}$ & $\begin{array}{l}\text { Three } \\
\text { dimensions of } \\
\text { cyst }\end{array}$ & Cyst Volume $\left(\mathrm{cm}^{3}\right)$ & $\begin{array}{l}\text { Lindgren } \\
\text { pre op }\end{array}$ & $\begin{array}{l}\text { Lindgren } \\
\text { postop }\end{array}$ \\
\hline 47 & 26 & $\mathrm{~F}$ & 0 & 0 & minimal & $3 \times 3.2 \times 2.2$ & 11.045 & 1 & 0 \\
\hline 48 & 58 & $\mathrm{~F}$ & 3 & 6 & severe & $3,5 \times 7 \times 2,5$ & 32.03 & 3 & 1 \\
\hline 49 & 38 & M & 2 & 2 & minimal & $3 \times 3 \times 2,5$ & 11.767 & 1 & 0 \\
\hline 50 & 54 & M & 1 & 4 & minimal & $6 \times 3 \times 1$ & 9.41 & 3 & 1 \\
\hline 51 & 43 & $\mathrm{~F}$ & 1 & 8 & moderate & $12 \times 5 \times 2,5$ & 78.45 & 2 & 0 \\
\hline 52 & 44 & M & 2 & 2 & severe & $8,5 \times 4,5 \times 1,5$ & 30.007 & 1 & 0 \\
\hline 53 & 56 & M & 1 & 2 & moderate & $5 \times 2 \times 2$ & 10.46 & 1 & 0 \\
\hline 54 & 43 & M & 2 & 0 & minimal & $5 \times 1,5 \times \mathbf{1}, \mathbf{2}$ & 4.707 & 1 & 0 \\
\hline 55 & 37 & M & 2 & 0 & minimal & $3 \times 6,5 \times 2$ & 20.39 & 1 & 0 \\
\hline 56 & 34 & M & 2 & 2 & minimal & $6,5 \times 2,5 \times 2$ & 16.997 & 1 & 0 \\
\hline 57 & 53 & M & 2 & 7 & severe & $8,5 \times 4 \times 3$ & 53.346 & 2 & 0 \\
\hline 58 & 48 & $\mathrm{~F}$ & 2 & 2 & minimal & $3 \times 6 \times 2,5$ & 23.535 & 3 & 1 \\
\hline 59 & 48 & M & 2 & 0 & moderate & $3.2 \times 2.8 \times 1,5$ & 7.029 & 1 & 0 \\
\hline 60 & 31 & M & 2 & 3 & moderate & $4,5 \times 1.7 \times 3$ & 12.002 & 2 & 0 \\
\hline 61 & 48 & $\mathrm{~F}$ & 2 & 2 & minimal & $5 \times 3 \times 2$ & 15.69 & 1 & 0 \\
\hline 62 & 58 & $\mathrm{~F}$ & 2 & 2 & minimal & $6.1 \times 2 \times 1.7$ & 10.847 & 3 & 0 \\
\hline 63 & 58 & $\mathrm{~F}$ & 3 & 5 & severe & $3.1 \times 6.9 \times \mathbf{2}, \mathbf{1}$ & 23.492 & 3 & 1 \\
\hline 64 & 54 & $\mathrm{~F}$ & 2 & 3 & moderate & $6.1 \times 2.6 \times \mathbf{2}, \mathbf{3}$ & 19.077 & 2 & 0 \\
\hline 65 & 27 & $F$ & 2 & 0 & moderate & $4.2 \times 1.8 \times \mathbf{1}, \mathbf{8}$ & 7.116 & 1 & 0 \\
\hline 66 & 50 & $\mathrm{~F}$ & 1 & 4 & minimal & $6,5 \times 3 \times 2$ & 20.397 & 2 & 0 \\
\hline 67 & 35 & M & 2 & 0 & minimal & $5 \times 1.2 \times \mathbf{1}, \mathbf{1}$ & 3.451 & 1 & 0 \\
\hline 68 & 53 & $\mathrm{~F}$ & 2 & 5 & severe & $5.9 \times 2,5 \times \mathbf{2}, \mathbf{4}$ & 18.51 & 2 & 1 \\
\hline 69 & 54 & $\mathrm{~F}$ & 1 & 3 & severe & $6 \times 2,5 \times \mathbf{1}, \mathbf{5}$ & 11.767 & 3 & 2 \\
\hline 70 & 47 & $\mathrm{~F}$ & 2 & 0 & minimal & $7.8 \times 2 \times \mathbf{1}, \mathbf{1}$ & 8.974 & 1 & 0 \\
\hline 71 & 58 & $\mathrm{~F}$ & 2 & 2 & severe & $8.4 \times 1.3 \times 1,2$ & 6.853 & 1 & 0 \\
\hline 72 & 57 & $\mathrm{~F}$ & 2 & 2 & minimal & $5.7 \times 2,5 \times 2$ & 14,905 & 2 & 1 \\
\hline 73 & 50 & $\mathrm{~F}$ & 2 & 3 & severe & $8,5 \times 4 \times 1,2$ & 21.338 & 2 & 1 \\
\hline 74 & 49 & $\mathrm{~F}$ & 2 & 2 & severe & $4,5 \times 2 \times 1,9$ & 8.943 & 1 & 0 \\
\hline 75 & 41 & $\mathrm{~F}$ & 0 & 2 & moderate & $7,5 \times 2 \times 2$ & 15.69 & 1 & 0 \\
\hline 76 & 51 & $F$ & 0 & 3 & severe & $5 \times 2,8 \times 2,7$ & 19.769 & 2 & 0 \\
\hline 77 & 47 & M & 2 & 0 & minimal & $5 \times 3 \times \mathbf{2}, \mathbf{1}$ & 16.474 & 1 & 0 \\
\hline 78 & 58 & $\mathrm{~F}$ & 2 & 2 & minimal & $5 \times 2 \times \mathbf{1}, \mathbf{3}$ & 6,799 & 2 & 0 \\
\hline 79 & 50 & $F$ & 2 & 7 & severe & $9 \times 4,5 \times \mathbf{2}$ & 42.363 & 2 & 0 \\
\hline 80 & 50 & M & 2 & 4 & severe & $5 \times 4,5 \times \mathbf{2}, \mathbf{1}$ & 24.711 & 3 & 2 \\
\hline 81 & 44 & F & 2 & 2 & moderate & $3.2 \times 1,5 \times \mathbf{1}, \mathbf{4}$ & 3.514 & 1 & 0 \\
\hline 82 & 58 & F & 0 & 4 & minimal & $3.6 \times 1.7 \times \mathbf{1}, \mathbf{6}$ & 5.121 & 2 & 1 \\
\hline 83 & 50 & K & 2 & 2 & severe & $9.2 \times 3 \times \mathbf{1}, \mathbf{2}$ & 17,321 & 2 & 0 \\
\hline 84 & 48 & M & 2 & 0 & minimal & $5 \times 2.29 \times 1$ & 5.988 & 1 & 0 \\
\hline 85 & 54 & $\mathrm{~F}$ & 2 & 4 & minimal & $8 \times 5 \times 1,1$ & 23.012 & 2 & 0 \\
\hline
\end{tabular}

For cyst volume calculation, the cyst radius was measured in three dimensions, and these measurements were entered into the USG device (Samsung HS50TM, South Korea). The device automatically calculates volumes using a standard formula for calculating the volume of ellipsoidal objects [26]. The degree of effusion was graded according to the study by Martí-Bonmatí et al. [14]. Effusion was classified as minimal: Grade 1 (liquid within lateral recesses or the suprapatellar bursa), moderate: Grade 2 (mild effusion, with both the lateral and suprapatellar recesses filled) or severe: Grade 3 (severe effusion associated with marked distension of the joint cavity). 
Table 2 Rauschning and Lindgren grading of knee joint symptoms ${ }^{a}$

\begin{tabular}{|c|c|c|c|c|}
\hline & Grade 0 & Grade 1 & Grade 2 & Grade 3 \\
\hline Swelling and pain & no swelling or pain & $\begin{array}{l}\text { slight swelling and discom- } \\
\text { fort after strenuous exercise }\end{array}$ & $\begin{array}{l}\text { moderate swelling and pain } \\
\text { following moderate exertion }\end{array}$ & $\begin{array}{l}\text { considerable and tense swell- } \\
\text { ing, severe pain interfering } \\
\text { with activities of daily living, } \\
\text { pain at rest }\end{array}$ \\
\hline Range of motion & $\begin{array}{l}\text { no limitation of range of } \\
\text { motion }\end{array}$ & $\begin{array}{l}\text { some giving-way or weak- } \\
\text { ness, muscular atrophy< } \\
1 \mathrm{~cm}\end{array}$ & $\begin{array}{l}\text { limitation of range of motion } \\
\text { between } 10 \text { and } 20 \text { degrees }\end{array}$ & $\begin{array}{l}\text { limitation of range of motion > } \\
20 \text { degrees }\end{array}$ \\
\hline Instability and weakness & no instability or weakness & $\begin{array}{l}\text { negligible limitation of range } \\
\text { of motion ( }<10 \text { degrees) }\end{array}$ & $\begin{array}{l}\text { slight or moderate instabil- } \\
\text { ity, locking, and muscular } \\
\text { atrophy } 1-2 \mathrm{~cm}\end{array}$ & $\begin{array}{l}\text { disabling instability, contrac- } \\
\text { tures, and muscular atrophy } \\
>2 \mathrm{~cm}\end{array}$ \\
\hline $\begin{array}{l}\text { The situation at work or } \\
\text { sports participation }\end{array}$ & $\begin{array}{l}\text { no limitation in work or } \\
\text { sports participation }\end{array}$ & $\begin{array}{l}\text { no hard labor, no elite sports } \\
\text { participation }\end{array}$ & $\begin{array}{l}\text { no physical work, limited } \\
\text { participation in sports }\end{array}$ & $\begin{array}{l}\text { stopped working due to knee } \\
\text { derangement, no participation } \\
\text { in sports }\end{array}$ \\
\hline
\end{tabular}

a Rauschning W, Lindgren PG. Popliteal cysts (Baker's cysts) in adults. I. Clinical and roentgenological results of operative excision. Acta Orthop Scand. 1979;50(5):583591

Table 3 The average values and standard deviations of meniscal tear, chondral lesion degree, effusion, Cystvolume, age, Lindgren pre-op, post-op, and Lindgren change

\begin{tabular}{|c|c|c|c|c|}
\hline \multicolumn{5}{|c|}{ Descriptive Statistics } \\
\hline & Minimum & Maximum & Mean & Std. Deviation \\
\hline Meniscal tear & 1,00 & 4,00 & 2,58 & 0,82 \\
\hline $\begin{array}{l}\text { Chondral lesion } \\
\text { degree }\end{array}$ & 1,00 & 8,00 & 2,94 & 1,71 \\
\hline Effusion & 1,00 & 3,00 & 1,88 & 0,86 \\
\hline Cyst volume & 3,45 & 78,45 & 17,25 & 12,63 \\
\hline Age & 22,00 & 59,00 & 46,86 & 9,17 \\
\hline Lindgren preop & 1,00 & 3,00 & 1,73 & 0,70 \\
\hline Lindgren postop & 0,00 & 1,00 & 0,29 & 0,46 \\
\hline Lindgren change & 1,00 & 3,00 & 1,40 & 0,54 \\
\hline
\end{tabular}

All raw data obtained from the calculations and measurements are listed in Table 1 . The average values and standard deviations of meniscal tear and chondral lesion degree, effusion, cyst volume, age, and Lindgren preoperative, postoperative, and Lindgren changes are listed in Table 2.

The IBM-SPSS 22 software was used for the statistical analysis to assess the relationship between variables using Spearman correlation tests, and to determine the strength and direction of these relationships. The Kolmogorov-Smirnov test was used to assess the normality of the distribution of data, whereas the preoperative and postoperative Lindgren values were evaluated using the Wilcoxon signed-rank test. Chondral lesion and cyst volume variables were recorded and analyzed for a possible relationship, where the statistical significance level was set as $\mathrm{p}<0.05$ Correlations (denoted as " $\mathrm{r}$ ") had different strengths [27]. The relationship between the degree of the chondral lesion and cyst volume was evaluated using the Spearman correlation test (total population) (see Table 5).

The relationship between the degree of chondral lesion and age, relationship between the degree of chondral lesion and the change in Lindgren score, relationship between the degree of chondral lesion and grade of effusion, and relationship between the grade of effusion and cyst volume were assessed using the Spearman rank correlation (Spearman's rho) test (see Table 3).

\section{Results}

Over the four-year follow-up period, USG and MRI were performed only in symptomatic patients. Overall, nine patients reported discomfort and pain during the followup period, with four patients undergoing USG imaging and four more undergoing MRI. A recurrent cyst was identified in two of these patients, with an overall incidence rate of $2.3 \%$.

The degree of the chondral lesion showed a moderate positive correlation with the cyst volume in the total population (Spearman's rho, correlation coefficient: 0.469, statistically significant at $\mathrm{p}=0.000<0.05$, see Table 2 ). The degree of the chondral lesion also showed a moderate positive correlation with age (Spearman's rho, correlation coefficient: 0.324 , statistically significant at $p=0.000$ $<0.05)$. The degree of the chondral lesion showed a moderate positive correlation with Lindgren's value change (Spearman's rho, correlation coefficient: 0.345 , statistically significant at $p=0.000<0.05$ ). The degree of the chondral lesion showed a moderate positive correlation with the degree of effusion (Spearman's rho, correlation coefficient: $0.492, \mathrm{p}<0.005)$. The cyst volume showed a weak positive correlation with the effusion degree (Spearman's rho, correlation coefficient: 0.20, the correlation being at the limits of statistical significance $p=0.07$ 


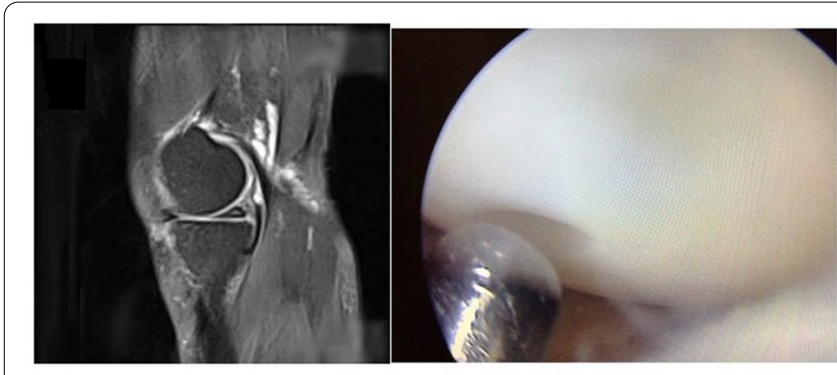

Grade I (T2-sagittal section) Grade I (Arthroscopic appearence )

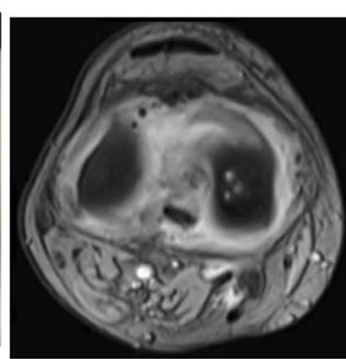

Grade II (T2-axial section )

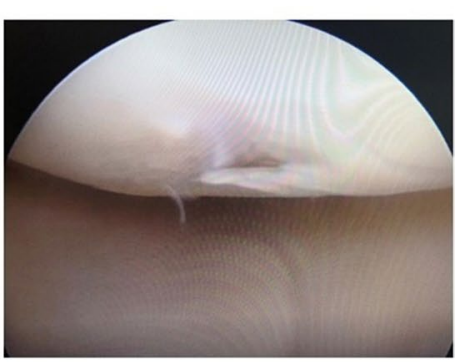

Grade II (Arthroscopic appearence )

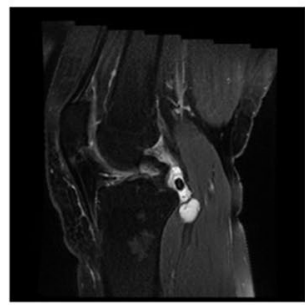

Grade III (T2-sagittal section)

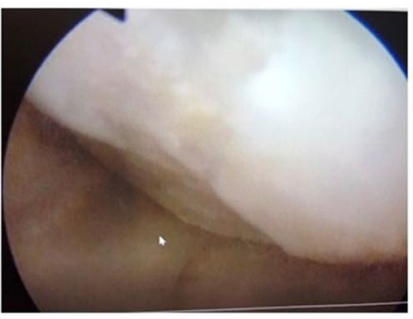

Grade III (Arthroscopic appearence )

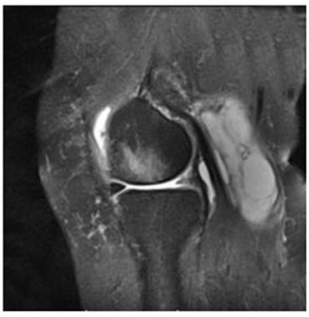

Grade IV (T2-sagittal section)

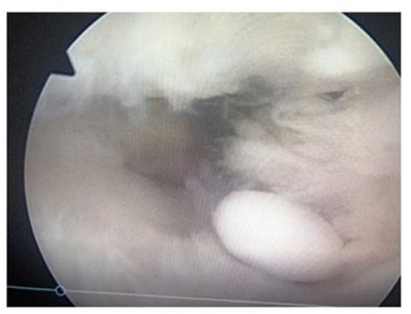

Grade IV (Arthroscopic appearence )

Case courtesy of Dr Murat Saylik and Ergin Sagtas

Fig. 1 Depicts the grade 1,2,3,4 chondral lesions according to the the outerbridge classification on MRI and arthroscopic images together
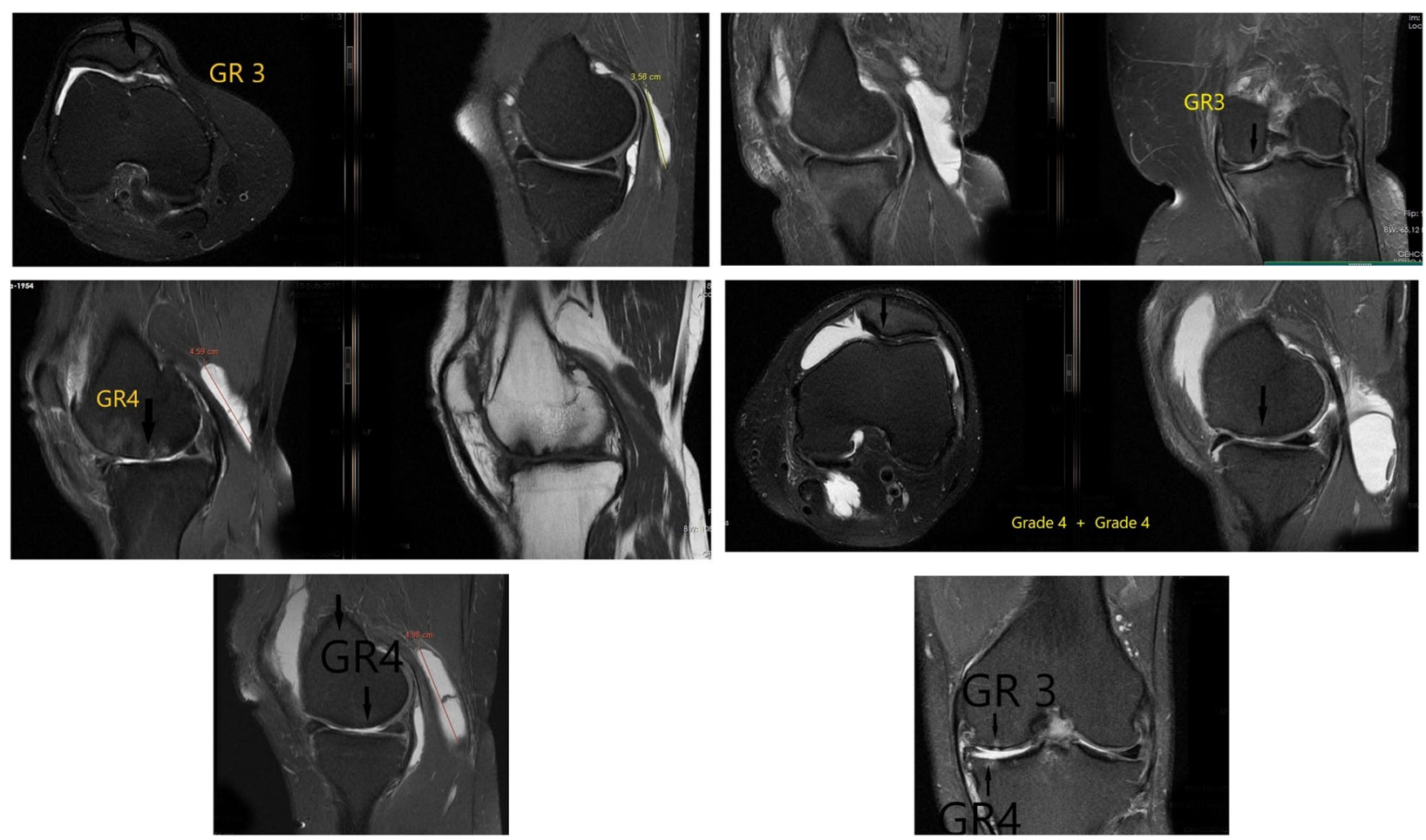

Fig. 2 The detailed MRI images of grade 3 and 4 lesions according to the the outerbridge classification 
Table 4 Outerbridge classification

\begin{tabular}{|c|c|}
\hline Grade & Description \\
\hline Grade 0 & normal cartilage \\
\hline Grade 1 & $\begin{array}{l}\text { signal intensity alterations with an intact surface of the } \\
\text { articular cartilage compared with the surrounding normal } \\
\text { cartilage }\end{array}$ \\
\hline Grade 2 & partial-thickness defect of the cartilage \\
\hline Grade 3 & fissuring of the cartilage to the level of the subchondral bone \\
\hline Grade 4 & exposed subchondral bone \\
\hline
\end{tabular}

$<0.08)$. There was no statistically significant relationship between age and cyst volume (Spearman's rho, $\mathrm{p}>0.05$ ). No significant correlation was found between meniscal tear and cyst volume, effusion degree, or change in Lindgren's value (Spearman's rho, $\mathrm{p}>0.05$ ). There was no statistically significant relationship between Lindgren value changes and cyst volume, effusion degree, and chondral lesion degree (Spearman's rho, $\mathrm{p}>0.05$ ).

\section{Discussion}

The possible correlation between cyst and intra-articular pathologies is a long-debated issue within the medical community. The literature review for the current study revealed that there were many articles on associations or relationships between intra-articular pathologies and Baker's cyst, which led us to divide the results into two groups. The first group included studies on the relationship between the degree of cartilage lesion, the degree of effusion, the degree of meniscal tear, and cyst volume [12-14], while the second group included studies on the association between cartilage lesions, effusion, meniscal tears, and the presence of cysts [15-22] (See Table 6).

Childress [15] was one of the first authors to show a strong association between medial meniscal tears and Baker's cysts. In their own evaluation of the MR images of 400 knees, Miller et al. [18] identified a significant relationship between the presence of a Baker's cyst and knee joint effusion, meniscal tears, and degenerative arthropathy, and accurately reported the coexistence of a Baker's cyst in $80.5 \%$ of cases of medial meniscal tear, $31 \%$ of cases of anterior cruciate ligament (ACL) rupture, 76.6\% of knee joint effusion, and $68 \%$ of degenerative knee joint osteoarthritis. Nevertheless, the coexistence of a Baker's cyst with medial plica, medial femoral chondral lesion, or lateral meniscal tear has not been evaluated, nor has the quantitative correlation between cyst volume and the degree of chondral lesion.

Stone et al. [16] and Sansone and De Ponti [17] investigated the association between meniscal tears and Baker's cysts. They found respectively that meniscal tears

Table 5 Correlations among age, imaging, and arthroscopic findings

\begin{tabular}{|c|c|c|c|c|c|c|c|c|}
\hline \multicolumn{9}{|l|}{ Correlations $^{c}$} \\
\hline & & & $\begin{array}{l}\text { Meniscal } \\
\text { tear degree }\end{array}$ & $\begin{array}{l}\text { Chondral } \\
\text { lesion } \\
\text { degree }\end{array}$ & Effusion & Cyst Volume & Age & $\begin{array}{l}\text { Lindgren } \\
\text { change } \\
\text { value }\end{array}$ \\
\hline \multirow[t]{12}{*}{ Spearman's rho } & Meniscal tear degree & Correlation Coefficient & 1,00 & $-0,13$ & 0,09 & $-0,10$ & 0,19 & 0,04 \\
\hline & & Sig. (2-tailed) & & 0,22 & 0,40 & 0,35 & 0,08 & 0,73 \\
\hline & Chondral lesion degree & Correlation Coefficient & $-0,13$ & 1,00 & $0,492^{* *}$ & $0,469^{* *}$ & $0,324^{* *}$ & $0,345^{* *}$ \\
\hline & & Sig. (2-tailed) & 0,22 & & 0,00 & 0,00 & 0,00 & 0,00 \\
\hline & Effusion & Correlation Coefficient & 0,09 & $0,492^{* *}$ & 1,00 & $0,20^{* * *}$ & 0,19 & 0,11 \\
\hline & & Sig. (2-tailed) & 0,40 & 0,00 & & $0,07^{* * *}$ & 0,08 & 0,32 \\
\hline & Cyst Volume & Correlation Coefficient & $-0,10$ & $0,469^{* *}$ & 0,20 & 1,00 & 0,07 & 0,13 \\
\hline & & Sig. (2-tailed) & 0,35 & 0,00 & 0,07 & & 0,53 & 0,24 \\
\hline & Age & Correlation Coefficient & 0,19 & $0,324^{* *}$ & 0,19 & 0,07 & 1,00 & $0,232^{*}$ \\
\hline & & Sig. (2-tailed) & 0,08 & 0,00 & 0,08 & 0,53 & & 0,03 \\
\hline & Lindgren change value & Correlation Coefficient & 0,04 & $0,345^{* *}$ & 0,11 & 0,13 & $0,232^{*}$ & 1,00 \\
\hline & & Sig. (2-tailed) & 0,73 & 0,00 & 0,32 & 0,24 & 0,03 & \\
\hline
\end{tabular}

(**) Correlation is significant at the 0.01 level (2-tailed)

$\left({ }^{*}\right)$ Correlation is significant at the 0.05 level (2-tailed)

c. Listwise $\mathrm{N}=85$

$\left(^{* *}\right)$ The correlation was at the limits of statistical significance $(p=0,07<0,08)$

r: Correlation coefficient, $r=0.100$ to $0.300=$ Weak correlation/relationship

$r=0.300$ to $0.500=$ Moderate (Fair) relationships/Medium correlation

$\mathrm{r}=0.600$ and above $=$ Strong relationship/high correlation 
Table 6 The literature concerning associations/ relations between the intraarticular pathologies and Baker cyst

\begin{tabular}{|c|c|c|c|c|c|c|c|c|}
\hline & $\begin{array}{l}\text { The number of } \\
\text { subjects }\end{array}$ & $\begin{array}{l}\text { Chondral } \\
\text { lesion degree } \\
\& \text { Cyst size } \\
\text { (positive } \\
\text { relationship) }\end{array}$ & $\begin{array}{l}\text { Meniscal } \\
\text { lesion degree } \\
\text { \& Cyst size } \\
\text { (positive rela- } \\
\text { tionship) }\end{array}$ & $\begin{array}{l}\text { Effusion } \\
\text { degree \& Cyst } \\
\text { size (positive } \\
\text { relationship) }\end{array}$ & $\begin{array}{l}\text { Plica exist- } \\
\text { ence \& Cyst } \\
\text { size (positive } \\
\text { relationship) }\end{array}$ & $\begin{array}{l}\text { Statistical } \\
\text { method }\end{array}$ & \multicolumn{2}{|l|}{ Quantification } \\
\hline $\begin{array}{l}\text { Vasilevska et al. } \\
\text { [12] }\end{array}$ & 66 & + & + & - & & $\begin{array}{l}\text { Chi-square test } \\
\text { and (Mann- } \\
\text { Whitney U test }\end{array}$ & \multicolumn{2}{|l|}{ weak } \\
\hline $\begin{array}{l}\text { Balık MS et al. } \\
{[13]}\end{array}$ & 45 & + & - & + & + & $\begin{array}{l}\text { Kolmogorov- } \\
\text { Smirnov test, } \\
\text { Mann-Whit- } \\
\text { ney U test and } \\
\text { Kruskal-Wallis } \\
\text { test }\end{array}$ & \multicolumn{2}{|l|}{ Strong } \\
\hline $\begin{array}{l}\text { Martí-Bonmatí } \\
\text { L, et al. [14] }\end{array}$ & 145 & - & + & + & - & $\begin{array}{l}\text { Pearson cor- } \\
\text { relation test }\end{array}$ & \multicolumn{2}{|l|}{ weak } \\
\hline Current study & 85 & + & - & + & - & $\begin{array}{l}\text { Spearman Cor- } \\
\text { relation test }\end{array}$ & \multicolumn{2}{|l|}{ Strong } \\
\hline \multicolumn{9}{|c|}{$\begin{array}{l}\text { The Current Literature that was concerning the association between the cartilage lesion, effusion, meniscal tear existence, and cyst exist- } \\
\text { ence }\end{array}$} \\
\hline & $\begin{array}{l}\text { The number of } \\
\text { subjects }\end{array}$ & $\begin{array}{l}\text { Chondral } \\
\text { lesion \& cyst } \\
\text { existence } \\
\text { association }\end{array}$ & $\begin{array}{l}\text { Meniscal tear \& } \\
\text { cyst existence } \\
\text { association }\end{array}$ & $\begin{array}{l}\text { Effusion } \\
\text { existence \& } \\
\text { cyst existence } \\
\text { association }\end{array}$ & $\begin{array}{l}\text { Plica exist- } \\
\text { ence \& Cyst } \\
\text { size (positive } \\
\text { relationship) }\end{array}$ & $\begin{array}{l}\text { Statistical } \\
\text { method }\end{array}$ & \multicolumn{2}{|c|}{ Quantification } \\
\hline $\begin{array}{l}\text { Peter Larking } \\
\text { [19] }\end{array}$ & Review article & - & + & - & - & $\begin{array}{l}\text { None (Because } \\
\text { the article } \\
\text { is report or } \\
\text { review) }\end{array}$ & \multicolumn{2}{|l|}{ None } \\
\hline $\begin{array}{l}\text { Yuelong Cao } \\
\text { et al. [20] }\end{array}$ & 105 & + & - & - & - & $\begin{array}{l}\text { Multivariate } \\
\text { logistic regres- } \\
\text { sion }\end{array}$ & \multicolumn{2}{|l|}{ None } \\
\hline $\begin{array}{l}\text { Rupp S, et al. } \\
\text { [21] }\end{array}$ & 100 & + & - & + & - & $\begin{array}{l}\text { Maentel-Haen- } \\
\text { szel test. }\end{array}$ & \multicolumn{2}{|l|}{ None } \\
\hline $\begin{array}{l}\text { Childress HM } \\
\text { (1970) [ 15] }\end{array}$ & 36 & - & + & - & - & $\begin{array}{l}\text { None (obser- } \\
\text { vational study) }\end{array}$ & None & $\begin{array}{l}\text { Early ages } \\
\text { (There was no } \\
\text { arthroscopy and } \\
\text { MRI) }\end{array}$ \\
\hline $\begin{array}{l}\text { Miller et al. } \\
\text { (1996) [18] }\end{array}$ & 400 & + & + & + & - & $\begin{array}{l}\text { Multivariate } \\
\text { logistic regres- } \\
\text { sion }\end{array}$ & \multicolumn{2}{|l|}{ None } \\
\hline $\begin{array}{l}\text { Sansone and } \\
\text { De Ponti } \\
\text { (1999) [17] }\end{array}$ & 46 & + & + & - & - & $\begin{array}{l}\text { Chi-Square } \\
\text { Statistic }\end{array}$ & \multicolumn{2}{|l|}{ None } \\
\hline $\begin{array}{l}\text { Stone KR, et al. } \\
\text { (1996) [16] }\end{array}$ & 238 & - & + & - & - & None & \multicolumn{2}{|l|}{ None } \\
\hline
\end{tabular}

occurred in $90 \%$ and $83 \%$ of knees in the presence of a popliteal cyst.

Although the literature has plenty of association reports, the quantification of cyst size, calculating the approximate volume, and a probable relationship between cartilage lesion degree, effusion degree, and cyst volume, were reported in only one study. Rupp et al. [21] reported that articular cartilage lesions are most often associated with popliteal cysts. They suggested that lesions of the articular cartilage play an essential role in the pathogenesis of secondary popliteal cysts. Low-grade chondral lesions and meniscal tears can be treated successfully by arthroscopic means, whereas arthroscopic surgery for high-grade chondral lesions often fails to eliminate effusion. This can be explained by the hypothesis that effusion facilitates fluid leakage through the valve from knee to gastrocnemius-semimembranosus bursa in adult patients.

The current study supports this hypothesis, with evidence of a direct correlation between cyst volume and the 
degree of chondral lesion. Rupp et al. [21] concluded that the grade of chondral lesions has a more critical effect on the outcome than the presence of meniscal lesions. In cases of degenerative osteoarthritis with grade III or grade IV lesions of the articular cartilage, addressing the intra-articular lesions with arthroscopic surgery to treat the popliteal cyst may be an unrealistic goal. In this study, we believe that it is possible to treat chondral lesions with meticulous evaluation and proper techniques. Cartilage lesions up to grade IV can be treated successfully with careful evaluation and appropriate bone marrow stimulation techniques (debridement, drilling, and microfracture) [28].

Wolfgang Rauschning's classic study [29] and Kim et al. [30] described the etiopathogenesis of popliteal (Baker's) cysts in detail, with illustrations, including the existence of capsular openings (communication links) between the gastrocnemius-semimembranosus bursa and the knee joint.

The slit-shaped capsular orifice acts as a funnel, opening during knee flexion due to the pulling force of the semimembranosus tendon and closing during extension because of the compressing forces of the overlying tendons.

If a capsular fold and its opening are present, they should be fully resected, and the remnant capsule should be reinforced with solid suturing materials that can withstand pressure changes caused by knee flexion-extension motions.

We believe that treating intra-articular pathologies and closing the valve, in addition to cyst excision, is helpful, and there have been published case series that reported good clinical results of this combination treatment [6].

Peter Larking [19], a senior research advisor, prepared a report in 2011 for the government of New Zealand. Although this article is a report presented to the government, the author widely reviewed the literature and examined the possibility of the coexistence of Baker's cysts and other knee pathologies. He emphasized the association between effusion, meniscal tear, degenerative arthritis, and Baker's cyst [19].

Cao et al. [20] found in their cross-sectional study that popliteal cysts or sub-gastrocnemius bursitis were significantly and positively associated with knee cartilage defects at the medial and lateral tibiofemoral sites before and after adjustment for age, sex, BMI, disease status, and knee radiographic features. Moreover, they also reported that, in multivariable analysis, both were significantly associated with medial tibiofemoral bone marrow lesions (BMLs), but not with lateral tibiofemoral BMLs. They graded cartilage defects and investigated the association between the presence of cysts and the degree of cartilage defects [20]. The main difference between this and the current study is that they targeted an older population, namely 50-79-year-olds, and thus did not exclude patients who had probable established osteoarthritis.

Furthermore, the relationship between intra-articular pathologies and cyst volume has been investigated and discussed in the literature (see Table 6). Martí-Bonmatí et al. [14] performed an MRI-based study in which cysts and cartilage lesions were categorized. Cyst volume was classified as absent, minimum, moderate, or massive. In contrast to the current study, cartilage lesions were categorized as either absent, chondropathy, or arthrosis. However, no relationship was reported between cyst volume and cartilage lesions.

In the current study, cartilage lesions were assessed using the Outerbridge classification, and cyst volume was measured using a formula to calculate the volume of ellipsoidal objects.

Initially, the Outerbridge classification was established to assess the degree of patellar cartilage lesions. In the current study, the Outerbridge classification was used because Kumm et al. [31] reported, when they examined the distribution of pathology in their knee MRI study, that cartilage lesions were more commonly seen in the patellar cartilage.

Although the current study had access to a relatively limited number of cases, it was possible to collect more numerical data, which helped to avoid bias and provide more accurate statistical results. In contrast with MartíBonmatí et al.'s [14] study, the current study demonstrated a direct and positive relationship between the degree of cartilage lesions and cyst volume.

We also noted that the amount of effusion and cyst volume was reported to be directly and positively related. Vasilevska et al. [12], in a study involving 66 patients, reported that the size of the Baker's cyst is strongly correlated with degenerative changes in the cartilage and with the degree of meniscus degeneration. However, contrary to both Martí-Bonmatí et al. [14] and Vasilevska et al. [12], the current study results did not show an effect of meniscal tear degree on the amount of effusion and cyst volume. We attribute this outcome to the distribution of meniscal tears in our group, where the majority consisted of Grades 0,1 , and 2 tears, in which the meniscal tears did not reach the joint surface and could not impair joint mechanics to cause effusion. In addition, these two studies did not quantify the Baker's cyst size by calculating the volume but instead classified their size as either large or small; furthermore, they measured cartilage thickness in the weight-bearing zone and classified cartilage degeneration as total (complete), subtotal, and absent. For our part, we quantified the size of the cyst by calculating the volume, which provided an advantage in statistical and mathematical accuracy. Additionally, our use of 
the Outerbridge classification with MRI and direct vision arthroscopy enabled us to quantify the degree of cartilage lesions. In the current study, there was a statistically significant correlation between knee effusion and cyst size.

Balik et al. [13] investigated the relationship between Baker's cyst volume and cartilage degeneration, effusion, and the existence of plica in 45 knees. They concluded that an increase in the degree of cartilage degeneration and the existence of medial plica could cause an increase in intra-articular effusion and cyst volume. This study was remarkably similar to ours and showed parallel results regarding the relationship between effusion, degree of cartilage lesion, and cyst volume. They also showed a similar approach in their results in terms of quantifying cartilage lesions and cyst size. In parallel with the current study, they found no significant correlation between meniscal tear grade and cyst volume. However, we quantified cartilage lesions using the Outerbridge classification and had access to a larger number of knees, which allowed a clearer delineation of the study.

One important distinction from the Balik et al. [13] analysis should be considered, namely the fact that we observed that some patients had more than one cartilage lesion., the combined impact was considered. We believe that this combination should be considered when examining the association between Baker's cyst volume and cartilage injury. We hypothesized that it would not be incorrect to suggest that knees with multiple chondral lesions may produce more chondral debris than knees with a single chondral lesion.

Another element of the current research that is distinct from the majority of the literature is the chosen patient population. Patients aged $>60$ years were excluded from the study to avoid any bias associated with age-related osteoarthritis.

In this study, the positive relationship between chondral lesion degree and Lindgren change value should be interpreted as an effective patient therapy, since intraarticular issues, such as chondral injury and meniscal tears, have been carefully handled.

In light of this study, surgeons' decisions in the management of Baker's cyst associated with the chondral lesion may lean towards cystic excision and the elimination of the chondral lesion.

The association between internal knee derangements (such as meniscal tears and cartilage lesions) and Baker's cysts is known. However, this study adds new quantitative information regarding the positive correlation between the combined cartilage lesion degree (as a combination of patellar cartilage, femoral and tibial condylar cartilage lesion degrees), effusion degree, and cyst volume in the young and middle-aged population.

The limitations of this study were that the calculation of the cyst volume yields approximate results, that it was retrospective in nature, and that it involved a relatively small number of patients.

Another limitation of the current study was that only symptomatic patients were evaluated postoperatively for recurrence with USG and MRI.

\section{Conclusion}

The current study revealed that the degree of the chondral lesion was significantly correlated with the amount of effusion and cyst volume in young and middle-aged patients with Baker's cysts. Moreover, the necessity of eliminating chondral lesions in addition to cyst excision in the treatment of Baker's cysts was also suggested.

\section{Abbreviations}

F: Female; M: Male; MRI: Magnetic Resonance Imaging; USG: Ultrasonography; OA: Osteoarthritis; BMI: Body Mass Index; BMLs: Bone Marrow Lesion ; ACL: Anterior Cruciate Ligament.

\section{Acknowledgments}

The authors would like to thank Jean-Yves Blanchard for English language editing. We would like to thank our mentor Professor Ahmet Turan Aydin for his exceptional mind and ideas regarding this study. We would also like to thank Erkan Goksu for providing the statistical work for our study.

\section{Authors' contributions}

MS contributed to the surgeries and collected the data. MS, KG, and MSS contributed to the literature review and established the discussion. MS, KG, and MSS were involved in drafting the manuscript or critically revising it for important intellectual content. MS produced the main ideas of this study. All authors read and approved the final manuscript. All authors approved the last version of the manuscript.

\section{Funding}

No funding was received for the support of this study. No benefits in any form have been or will be received from a commercial party related directly or indirectly to the subject of this manuscript.

\section{Availability of data and materials}

The degree of the chondral lesions and the cyst volumes with cyst diameters (for justification of calculation results) generated or analyzed during this study are included in this published article (see Table 1).

The other datasets during and/or analyzed during the current study are available from the corresponding author upon reasonable request.

\section{Declarations}

\section{Ethics approval and consent to participate}

This study was approved by the ethical committee of the Bursa Medical Park Hospital. Written informed consent was obtained from all the patients. Written informed consent was obtained from all patients to participate in this study.

Consent for publication

Not applicable. 


\section{Competing interests}

The authors declare no conflicts of interest. No benefits in any form have been or will be received from any commercial entity that is directly or indirectly related to this work.

\section{Author details}

'Department of Orthopaedic Surgery, Istinye University Medical Faculty, Topkapı Kampüsü, Maltepe Mah, Edirne Çırpıcı Yolu, No.9 Zeytinburnu, 34010 istanbul, Turkey. ${ }^{2}$ Department of Orthopaedics and Traumatology, Baskent University Alanya Research and Practice Center, Saray Mahallesi Yunus Emre Caddesi No:1 07400, Alanya, Antalya, Turkey.

Received: 13 March 2021 Accepted: 9 September 2021

Published online: 05 October 2021

\section{References}

1. Jiang J, Ni L. Arthroscopic internal drainage and cystectomy of popliteal cyst in knee osteoarthritis. J Orthop Surg Res. 2017;12(1):182. https://doi. org/10.1186/s13018-017-0670-4.

2. Rauschning W. Popliteal cysts and their relation to the gastrocnemi -semimembranosus bursa. Studies on surgical and functional anatomy. Acta Orthop Scand Suppl. 1979:179:1-43.

3. Adams R. Chronic rheumatic arthritis of the knee joint. Dublin J Med Sci. 1840;17:520-2.

4. Gristina AG, Wilson PD. Popliteal cysts in adults and children. A review of 90 cases. Arch Surg. 1964:88:357-63.

5. Wigley RD. Popliteal cysts: Variations on a theme of Baker. Semin Arthritis Rheum. 1982;12:1-10.

6. Saylik M, Gökkuş K. Treatment of baker cyst, by using open posterior cystectomy and supine arthroscopy on recalcitrant cases (103 knees). BMC Musculoskelet Disord. 2016:17(1):435

7. Canoso JJ, Goldsmith MR, Gerzof SG, Wohlgethan JR. Foucher's sign of the Baker's cyst. Ann Rheum Dis. 1987;46(3):228-32. https://doi.org/10. 1136/ard.46.3.228

8. Baker WM. On the formation of the synovial cysts in the leg in connection with disease of the knee joint. Vol 13. London: St Bartholomew's Hospital Report: 1877. p. 245-61.

9. Curl WW. Popliteal Cysts: Historical Background and Current Knowledge. J Am Acad Orthop Surg. 1996;4(3):129-33

10. Sansone V, de Ponti A, Paluello GM, del Maschio A. Popliteal cysts and associated disorders of the knee. Critical review with MR imaging. Int Orthop. 1995:19(5):275-9. https://doi.org/10.1007/BF00181107.

11. Demir DG, Altan L, Diraz N. Ruptured Baker's Cycst Mimicking the Symptoms of Deep Vein Thrombosis in a Rheumatoid Arthritis Patient. Arch Rheumatol. 2008;23(2):63-5.

12. Vasilevska V, Szeimies U, Staebler A. MRI diagnosis of Baker cyst and significance of associated medial compartment knee osteoarthritis. Radiol Oncol. 2008;42(2):51-8.

13. Balik MS, Turan A, Celik FB. Is There A Relationship Between Three-Dimensionally Measured Baker's Cyst Volume and Knee Pathologies? Eurasian J Med. 2019:51(1):64-9.

14. Martí-Bonmatí L, Mollá E, Dosdá R, Casillas C, Ferrer P. MR imaging of Baker cysts --prevalence and relation to internal derangements of the knee. MAGMA. 2000;10(3):205-10.

15. Childress HM. Popliteal cysts associated with undiagnosed posterio lesions of the medial meniscus. The significance of age in diagnosis and treatment. J Bone Jt Surg Am. 1970;52:1487-92.
16. Stone KR, Stoller D, De Carli A, Day R, Richnak J. The frequency of Baker's cysts associated with meniscal tears. Am J Sports Med. 1996:24:670-1.

17. Sansone V, De Ponti A. Arthroscopic treatment of popliteal cyst and associated intra-articular knee disorders in adults. Arthroscopy. 1999;15:368-72.

18. Miller TT, Staron RB, Koenigsberg T, Levin TL, Feldman F. MR imaging of Baker cysts: association with internal derangement, effusion, and degenerative arthropathy. Radiology. 1996;201:247-50.

19. Larking P. Causation Review - Popliteal Cysts/Baker's Cyst of the knee. Governance, Policy and Research, ACC, 03- 2011.

20. Cao Y, Jones G, Han W, Antony B, Wang X, Cicuttini F. Ding Popliteal cysts and subgastrocnemius bursitis are associated with knee symptoms and structural abnormalities in older adults: a cross-sectional study. Arthritis Res Ther. 2014;16(2):R59.

21. Rupp S, Seil R, Jochum P, Kohn D. Popliteal cysts in adults. Prevalence associated intraarticular lesions and results after arthroscopic treatment. Am J Sports Med. 2002;30:112-5.

22. Artul S, Jabaly-Habib H, Artoul F, Habib G. The association between Baker's cyst and medial meniscal tear in patients with symptomatic knee using ultrasonography. Clin Imaging. 2015;39(4):659-61.

23. Tschirch FT, Schmid MR, Pfirrmann CW, Romero J, Hodler J, Zanetti M. Prevalence and size of meniscal cysts, ganglionic cysts, synovial cysts of the popliteal space, fluid-filled bursae, and other fluid collections in asymptomatic knees on MR imaging. AJR Am J Roentgenol. 2003;180(5):1431-6.

24. Outerbridge RE. The etiology of chondromalacia patellae. J Bone Joint Surg Br. 1961;43-B(4):752-7.

25. Greis PE, Bardana DD, Holmstrom MC, Burks RT. Meniscal injury: I. Basic science and evaluation. J Am Acad Orthop Surg. 2002;10(3):168-76.

26. Bae KT, Tao C, Wang J, Kaya D, Wu Z, Bae JT, et al. Consortium for Radiologic Imaging Studies of Polycystic Kidney Disease (CRISP). Novel approach to estimate kidney and cyst volumes using mid-slice magnetic resonance images in polycystic kidney disease. Am J Nephrol. 2013;38(4):333-41.

27. Chan YH. Biostatistics 104: correlational analysis. Singapore Med J. 2003;44(12):614-9.

28. Gill TJ, Steadman JR. Bone Marrow Stimulation Techniques: Microfracture, Drilling, and Abrasion. In: Articular Cartilage Lesions. New York, NY: Springer; 2004. https://doi.org/10.1007/978-0-387-21553-2_7.

29. Rauschning W. Anatomy and function of the communication between knee joint and popliteal bursae. Ann Rheum Dis. 1980;39(4):354-8. https://doi.org/10.1136/ard.39.4.354.

30. Kim Kl, Lee SH, Ahn JH, Kim JS. Arthroscopic anatomic study of posteromedial joint capsule in knee joint associated with popliteal cyst. Arch Orthop Trauma Surg. 2014;134(7):979-84. https://doi.org/10.1007/ s00402-014-2001-0.

31. Kumm J, Turkiewicz A, Zhang F, Englund M. Structural abnormalities detected by knee magnetic resonance imaging are common in middleaged subjects with and without risk factors for osteoarthritis. Acta Orthop. 2018:89(5):535-40. https://doi.org/10.1080/17453674.2018.1495164.

\section{Publisher's Note}

Springer Nature remains neutral with regard to jurisdictional claims in published maps and institutional affiliations. 